\title{
Basal Cell Carcinoma Originating from a Posttraumatic Scar at the Intergluteal Sulcus
}

\author{
(D) Gökhan Okan¹, (D) Murat Bayar², (1) Cuyan Demirkesen³, (D) Sıdıka Kurul ${ }^{4}$ \\ 1Private Dermatologist, Istanbul, Turkey \\ 2Spectromar Radiology Center, Istanbul, Turkey \\ ${ }^{3}$ Acibadem University Faculty of Medicine, Department of Pathology, Istanbul, Turkey \\ ${ }^{4}$ Istanbul University Istanbul Faculty of Medicine, Department of Plastic and Reconstructive Surgery, Surgical Oncology Unit, Istanbul, Turkey
}

\section{Dear Editor,}

Basal cell carcinoma $(\mathrm{BCC})$ is the most skin tumour. Chronic sun exposure is considered as the main etiologic factor in its development. We report a patient with perianal BCC which developed after trauma.

A 73-year-old woman presented with a one-year history of an erythematous ulcer on her intergluteal sulcus. The skin lesion grew gradually, but did not cause pain, bleeding or gastrointestinal symptoms. Her past medical history included hypertension, insulindependent diabetes mellitus and significant fall from the stairs five years ago on the ulcer site with a large wound that healed with secondary intention.

On examination, a single $4 \times 4 \mathrm{~cm}$, erythematous, asymptomatic ulcer with raised borders was observed in the intergluteal sulcus. A diagnostic punch biopsy was performed from the margin of the erosion. Histopathologic analysis demonstrated an ulcerated tumour within the dermis, composed of islands of basaloid cells, with palisading of the cells at the periphery. The tumour displayed an infiltrative pattern of growth. Besides the infiltrating type, micronodular and multifocal superficial types were also evident. These findings were consistent with mixed type BCC and total excision was suggested for treatment (Figure 1a, 1b). Computed tomography of the pelvis demonstrated an old fracture with subluxation at the sacrococcygeal joint. There were fuzzy amorphous densities showing posttraumatic soft fibrotic tissue (Figure 2). There were no evidence of metastatic disease. Local wide resection was performed with an intraoperative margin evaluation. The defect was closed with a Limberg flap (Figure 3a, 3b, 3c). Histopathologic examination of the total excision material was also found to be consistent with mixed type BCC. The surgical resection margin was free of malignant cell involvement. Complications or recurrences were not noted during the follow- up period.
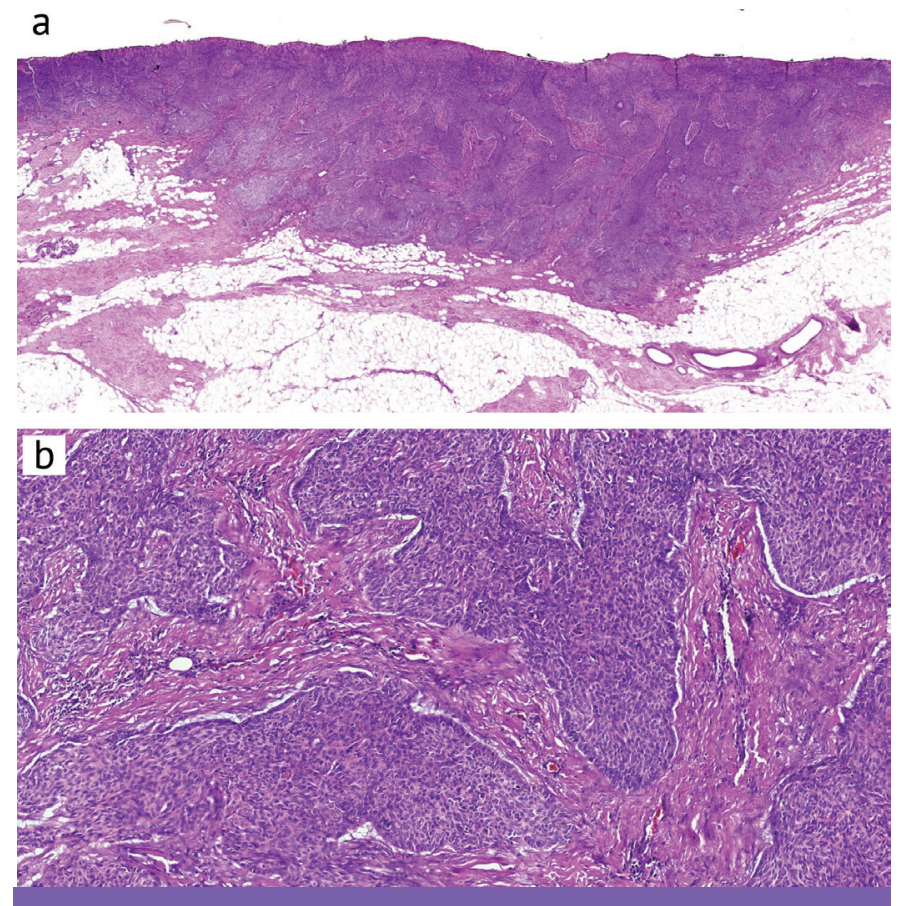

Figure 1. a, b) Islands of basaloid tumour cells with peripheral palisading [hematoxylin and eosin (HE) x20, HE x200] 


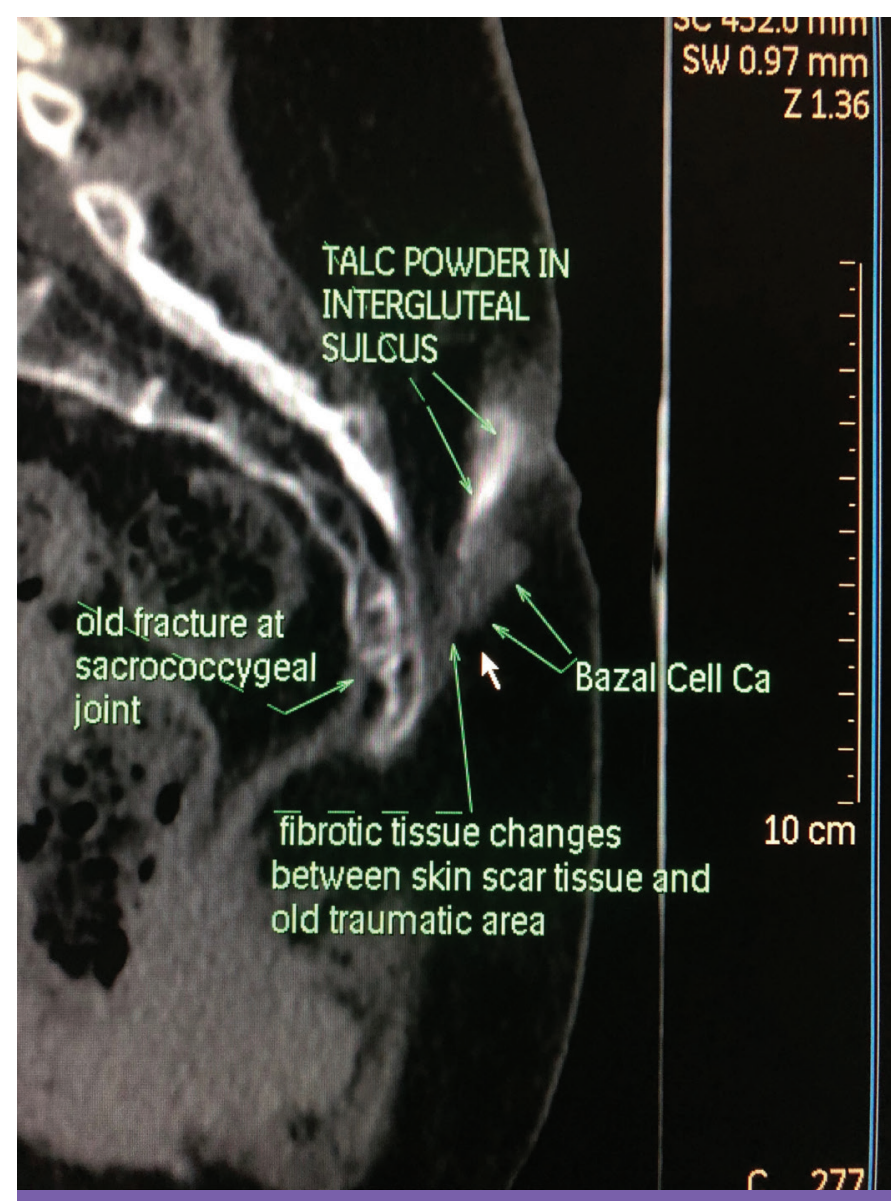

Figure 2. Sagittal computed tomography of the pelvis: Irregularities between skin scar tissue and old traumatic area (arrow), basal cell cancer (double arrow), old fracture at sacrococcygeal joint (stars), talc powder on the intergluteal sulcus (triple arrow)
BCC rarely occurs in the anogenital region among older individuals [1]. It varies from erythematous papules and patches to nodules, plaques, and ulcers with bleeding, discomfort, itching, and mucoid discharge. Our patient had an erythematous ulcer without symptoms. The etiology of perianal BCC remains unknown. Chronic irritation, trauma, immunosuppressive medications, radiation and scars are reported causative factors [2].

Scar tissue-related BCC is rare, but BCC can develop from nonhealing wounds, keloid tissues and previous surgical or vaccination scars. Healing by secondary intention is the most important risk factor in scar tissue-related BCC [3]. Our patient's wound healed by secondary intention. The pathogenesis of malignancy accompanied by trauma is vague. Chronic irritation, depressed cellular immunity, misplacement of epithelial cells, and tumour suppressor gene mutations have been identified as etiological factors for BCC in scar tissues. Mixed type BCC is an aggressive form of the tumour. This is prone to recurrence and develops mostly in the face and scalp [4]. The histopathological examination showed mixed type tumour and localised at the perianal area. A wide resection was performed. Arons et al. [5] proposed the following criteria to show the correlation between trauma and BCCs a) severe injury, b) normal skin integrity and absence of tumour before trauma, c) tumour related to the site of trauma or originating within boundaries of the injury, d) reasonable latent period, and e) tumour compatible with scar tissue. Our patient had a history of trauma on the tumour site with a wound that healed with secondary intention. Before the fall, she did not have BCC and notable risk factors.

This case illustrates the importance of long-term monitoring of areas not exposed to sunlight following trauma among older persons.
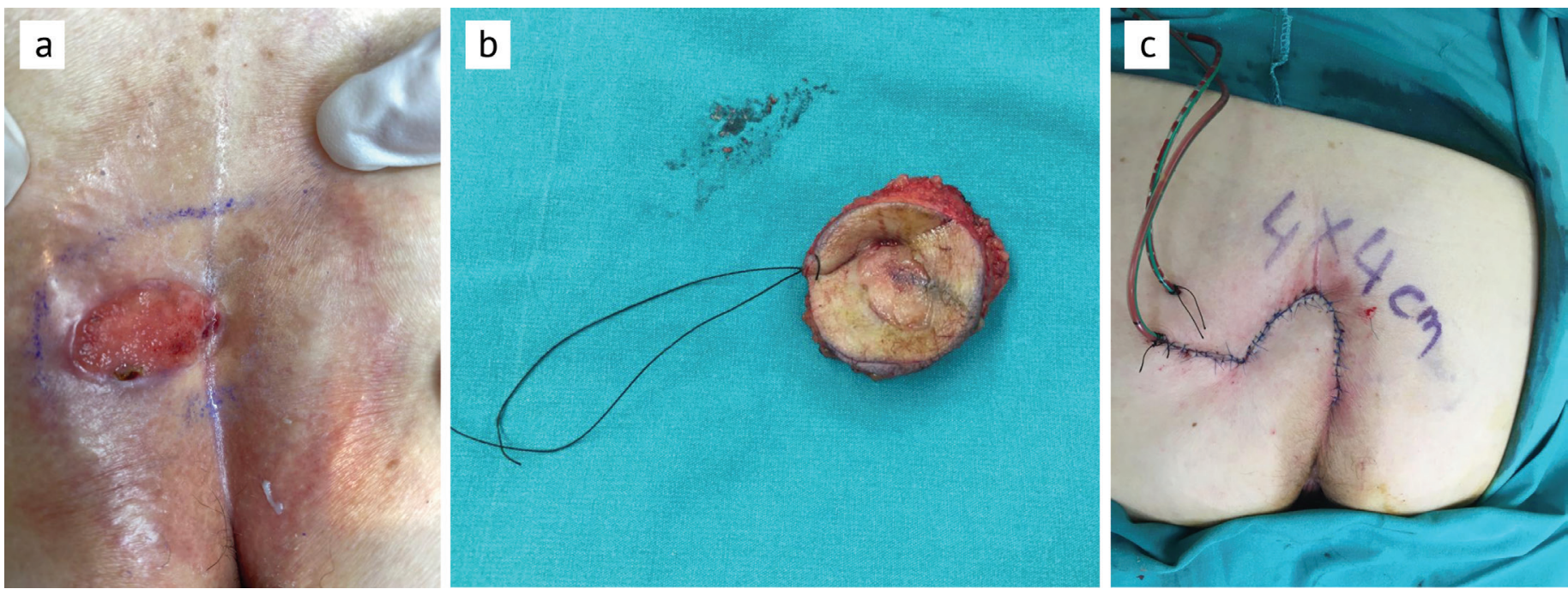

Figure 3. a) An ulcerated lesion at the intergluteal sulcus. b) Surgical specimen. c) Defect closure with Limberg flap 


\section{Ethics}

Informed Consent: Consent form was filled out by all participants.

Peer-review: Externally peer-reviewed.

\section{Authorship Contributions}

Surgical and Medical Practices: G.O., C.D., S.K., Concept: G.O., M.B., C.D., S.K., Design: G.O., M.B., S.K., Data Collection or Processing: G.O., M.B., C.D., S.K., Analysis or Interpretation: G.O., C.D., Literature Search: G.O., Writing: G.O., C.D., S.K.

Conflict of Interest: No conflict of interest was declared by the authors.

Financial Disclosure: The authors declared that this study received no financial support.

\section{References}

1. Meeks MW, Grace S, Montenegro G, Schoen MW, Carpenter D, Lai JP, Poddar N. Perianal basal cell carcinoma J Gastrointest Cancer 2019;50:641-643.

2. Gibson GE, Ahmed I. Perianal and genital basal cell carcinoma: A clinicopathologic review of 51 cases. J Am Acad Dermatol 2001;45:68-71.

3. Ünverdi ÖF, Yücel S. Basal Cell Carcinomas in Trauma-Related Scar Tissue: A Rare Case Series. Adv Skin Wound Care 2020;33:1-3.

4. Turhan-Haktanir N, Dilek FH, Demir Y, Sahin O. Presence of interferon regulatory factor-1 in aggressive and nonaggressive histological variants of basal cell carcinoma specimens. J Cutan Aesthet Surg 2010;3:34-37.

5. Arons MS, Lynch JB, Lewis SR, Blocker TG. Scar tissue carcinoma. I. A clinical study with special reference to burn scar carcinoma. Ann Surg 1965;161:170188. 